\title{
The Loss and Return of Chinese Culture in English Teaching: Teaching Design of Chinese Tea Culture in English Class Based on ADDIE Model
}

\author{
Liu Yang ${ }^{1} \&$ Yang Congzhou ${ }^{1}$ \\ ${ }^{1}$ English Department, North China Electric Power University, Baoding, China \\ Correspondence: Yang Congzhou, English Department, North China Electric Power University, 071000 Hebei, \\ China.
}

Received: July 8, 2019 Accepted: September 26, $2019 \quad$ Online Published: October 28, 2019

doi:10.5539/ies.v12n11p187

URL: https://doi.org/10.5539/ies.v12n11p187

\begin{abstract}
Since the 21st century, China has put forward the "going out strategy of Chinese culture" which aims at realizing the awakening, reviving, integrating and spreading of Chinese culture. China emphasizes strengthening and improving the spreading of Chinese culture in order to enhance the soft power of national culture. China needs to cultivate intercultural communicative talents that can display Chinese culture to the world through an appropriate path with profound intercultural communication awareness and excellent intercultural communicative competence. Being representative of Chinese traditional culture, tea culture carries a long history of China. This paper takes the tea culture as an example for teaching design from the aspects of analysis, design, development, implementation, and evaluation based on the ADDIE model, aiming at optimizing the teaching design of Chinese culture into English teaching and cultivating students' intercultural communicative ability.
\end{abstract}

Keywords: ADDIE model, Chinese culture, teaching design, tea culture, intercultural communicative competence

\section{Introduction}

Different eras require different talents and the target of education changes accordingly. With today's background of globalization, the development of economy and community consciousness of "co-building and co-sharing" in China have further strengthened the ties between China and the rest of the world. To realize the "going out strategy of Chinese culture", it's necessary to train a group of talents with intercultural communicative competence that requires learners to break through cultural barriers and understand the way of thinking as well as lifestyle of communicators. The latest Guidelines on College English Teaching instructs that College English teaching aims to train the students' application ability and to enhance the intercultural communicative consciousness and communicative competence, developing the ability of autonomous learning and improving the comprehensive cultural literacy of students (Wang, 2018). This teaching goal puts emphasis on the importance of intercultural awareness and communicative competence. Many Chinese scholars have done a lot of research on intercultural communication. Hu (2013) discussed the orientation of intercultural communicative competence in Chinese foreign language teaching and put forward that "acquiring intercultural communicative competence is a lifelong activity." Yang and Zhuang (2007) constructed the framework of intercultural communication which provided the theoretical basis for the study of intercultural communication ability in China. Zhang (2007) believed that intercultural communicative competence "requires learners to transcend the shackles of their own language and target language as well as their corresponding specific cultures and to understand various ways of thinking and lifestyles, cultivating flexible communicative competence suitable for a variety of social and cultural environments." With definitions of intercultural communicative competence, it can be seen that intercultural communication is a two-way process that is not limited to the adaptability of the target language environment. Intercultural communication is communication between the two cultures. As the carrier of culture, language undertakes the task of absorbing and disseminating culture. However, there is a "tendency to pay too much attention to the intake of western cultures and to ignore the export of Chinese cultures in English teaching" in China (Huang, 2015). The absence of cultural export has led many students to ignore the study and dissemination of Chinese traditional culture. 
Foreign language class is a door between students and the outside world through which students can experience the charm of world culture. This door cannot keep our learners in the house tightly. English education needs to encourage students to step out of this door and go to the world stage to carry forward Chinese culture. As the second-largest economic entity in the world, China's trade exchanges with other countries remarkably maintain constant and rapid growth. The export of Chinese tea has also increased and the approbation of Chinese tea is getting higher and higher all over the world. Tea is transported abroad as a commodity and tea culture goes to the world with it. Tea culture has an indisputable position in the traditional Chinese culture because its unique characteristics have painted a brilliant picture in the blueprint of Chinese culture. Tea culture not only contains tea art, tea ceremony, tea sets and so on but also relates to Chinese philosophy, Confucian spirit and traditional Chinese medicine ideology. Besides, tea culture also has the advanced nature of keeping pace with the times. It began in the era of Shennong (the mythical Chinese inventor of Chinese agriculture). With the development of times, tea culture has been continuously adjusted, evolved, combined with the trend of times and gradually developed a regional and distinctive culture. All in all, this paper attempts to find a way to integrate Chinese culture into English teaching and design through scientific methods.

\section{ADDIE Model}

ADDIE model is a classic teaching development model (see Figure 1). It was first used in military training in the US and has developed into a methodology of educational technology (Xu, 2017). At present, the ADDIE model is widely used in military training, enterprise training and teaching. In China, the application of the ADDIE model in flipping class (Yao \& Wang, 2017; Qi, 2016) micro-class (Bu, 2014) has made some achievements. The ADDIE model consists of five-step components and the initials of the five components are taken as the name ADDIE in which A represents ANALYZE, the first D means DESIGN and the second D means DEVELOP while I equals IMPLEMENT and E is EVALUATE. The solid line represents the process from analysis to evaluation while the dotted line represents the feedback path. The whole model is not a simple linear but a dynamic cyclic process in that the relationship between each two parts is not a procedural relation but a logical connection. Teaching design is not a process from scratch and it can be a beginning at any stage. That is to say, any part of the ADDIE model may be the starting point of teaching design so that designers can return to any step to do introspection and improvement (see Figure 1).

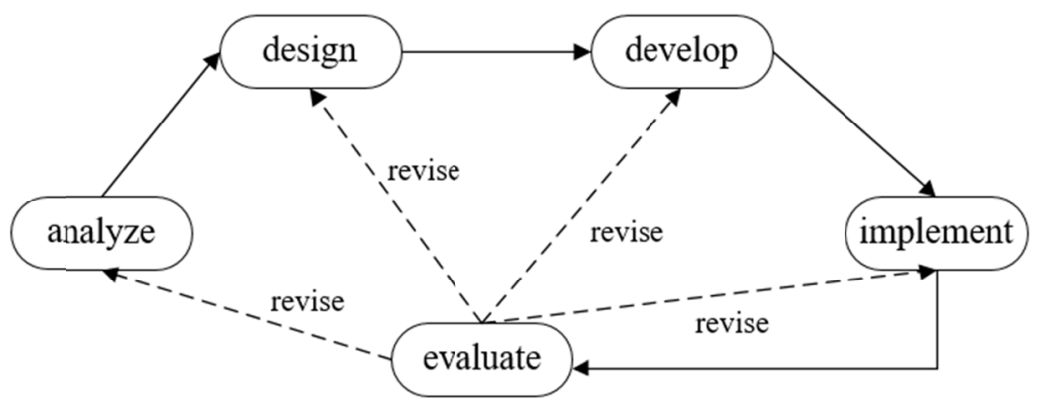

Figure 1. The ADDIE model

\section{Teaching Design of Tea Culture Based on ADDIE Model}

\subsection{Analyze}

ANALYZE is the prework of teaching design. As the designer, teachers should thoroughly analyze the characteristics, teaching resources and requirements of students. In teaching design, it's imperative to put forward the problem that "What kind of problem can be solved by teaching?" (Gagné et al., 2005). College English teaching is a kind of education that uses English as a medium or a tool to understand the world and the culture to form the consciousness of cultural exchange. The course content is cultural. Learning Chinese cultural knowledge and its English expression is needed by all students of various professional fields of universities. Therefore, when analyzing the teaching needs, the questions we put forward can be "What kind of Chinese cultural knowledge should be known by students from different majors " or "How to design college English Chinese cultural courses so that students of different majors can develop the ability to solve the cultural communication problems encountered in their future work, study and life". 
The first step in ANALYZE is requirement analysis, answering the question "Why we teach this knowledge." Kaufman (1996) and Rossett (1988) think that the need is the difference between the expected state and the current state of the event. Formally speaking, need is the gap in results. Because of the gap, learning is required and teaching design needed to be carried out. For example, when college students are talking about Chinese tea culture in foreign situations, when some English expressions of tea name, variety, efficacy, origin, etc. are crucial and if the students do not have the relevant intellectual skill, verbal information, cognitive strategy, motor skill and attitude, there will be hiatus exists in their final communicative fruit, resulting in communicative obstacles and even communicative failure. This gap is the problem that teaching needs to solve. This gap exists among not only English majors but any college students who are about to face the challenge of intercultural communication. For the teaching requirements of tea culture, it can be analyzed from several aspects: external needs, internal needs, basic needs and practical needs.

External needs include needs triggered by external factors such as society, workplace and so on. This kind of needs pays attention to the problem of learners' external environment that teachers must face. Under the historical background of "the going out strategy of Chinese culture", it's the duty of college students to spread Chinese culture abroad in a variety of ways by diversified channels. The English expression of Chinese culture is the times and society's requirement and challenge to students.

Internal needs pay attention to the personal development of students, focusing on answering the question: "Can learning this course help students become a better one?" Studying Chinese culture can not only profound students' patriotism but also improve the cultural literacy and ideological height of the individual. The dissemination of Chinese culture can improve students' artistic taste, raise their moral level and widen their social scope.

Basic needs emphasize prerequisites. In this aspect, the question that needs to be answered is "What are the basics of teaching or learning in this tutorial?" It is evident that if one can carry out intercultural communication successfully and introduce Chinese culture in English smoothly, he/she must have learning performance that is, verbal information which refers to knowledge that can be "stated" (Gagné et al., 2005). For example, to introduce Chinese tea culture, a student must be able to master a specific understanding of tea cultures such as tea terminology, tea art, the connotation of teaism, and even terms and appreciations of tea poems and tea paintings. These highly organized pieces of information must be stored in mind for extraction and the extracted knowledge should be expressed in English. Therefore, when doing the teaching design, Chinese culture and its English expression should be put as the foundation of the course.

The practical needs focus on the problem of what kind of tutorial can connect the knowledge learned with the actual application situation to the greatest extent. Teaching needs to consider whether the teaching process needs to create a real situation to learn and how to carry on the teaching design to maximize situational learning. Intercultural ability needs to be developed and tested in practice. Therefore, tea culture teaching needs to create a particular situation for students to learn and its teaching design needs some resources: multimedia classroom, tea set for demonstration, tea culture-related video, picture materials and so on.

The second step of ANALYZE resulted analysis that analyzes the expected students' cognitive mastery, emotional output and skill acquisition after tea culture teaching. At this stage, we should emphasize what students can master rather than what students can understand. Students can use English to introduce the knowledge of tea culture, using some language skills to explain, demonstrate and join their own understanding of the tea culture. This goal far exceeds the requirement for students to "understand" tea culture, emphasizing more skills and a positive attitude towards the dissemination of Chinese culture. Mastery and understanding are two different levels in the process of students' learning in which understanding functions as the base and mastery functions as the result. Taking the tea culture class as an example, the understanding is to make the learners receive relevant tea culture knowledge through the teaching activities of the teacher's cultural presentation, the information presentation, the knowledge explanation and so on. These are the declarative knowledge which refers to the indirect acquisition of the students about the historical development of the tea, the tea science and technology, the tea and the tea set, tea-drinking custom, tea ceremony, tea art and other knowledge. The mastery is the practical application skill developed after students' acquisition of theoretical knowledge. After learning the basic knowledge of the tea culture, the students can narrate the spirit of the tea, the tea book, the tea painting, the tea poem's evaluation and express the personal attitude.

\subsection{Design}

The purpose of the design is to provide guidance for teaching and learning as well. The design is based on teaching needs and objectives. No course has an exclusive design, the design itself is a dynamic, creative process 
and the design of any course may be multi-modal. Tea culture includes a wide range and deep connotations so the design part follows the following sequence:

(1) Determine the highest level of learning results that students can achieve after learning this course. At the end of the teaching, students are hoped to master the following skills: intellectual skill, cognitive strategy, attitude, verbal information and motor skill. The connotation of intellectual skill is to do things with symbols in that students can acquire the ability to express and display tea culture properly in English. After "Understanding the rules" (English expression of tea culture), the ability to "applicating the rules" is cultivated. The cognitive strategy is the ability to control one's behavior. Skinner (1968) defines cognitive ability as "self-management behavior." Van Merriënboer, Clark, and de Croock (2002) hold that effective auxiliary information for the development of cognitive strategies is "supportive information", that is, examples. When teaching English expression of tea culture, teachers give examples that can be used as a reference for learners to imitate. The cognitive strategy is developed from the experience. The ability to acquire the ability to disseminate Chinese culture takes long, so it is necessary for teachers to provide a variety of situations for the students so that they can summarize in practice. Attitude needs to pay attention to students' attitudes toward Chinese culture, learning the dissemination of Chinese culture. The intensity of a person's attitude towards a project can be shown by the number of times they choose or avoid it in a variety of circumstances. However, because this study lasted too long and we could not guarantee that every student could participate in intercultural communication activities, we based our inference on attitude on "self-report", that is, to survey their attitude before and after teaching (see Appendix A). Verbal information has been explained in the process of aforesaid "ANALYZE".

(2) Determine the theme and components of teaching. For example, if the teaching theme of a class is "Introduction to Chinese Tea Culture in English", the elements of the lesson are divided into 1) The teaching of tea classification terms: green tea, black tea, oolong tea or green tea, yellow tea, white tea. 2) Tea name translation teaching: Tie Guanyin/tat-kuan-yin tea/Iron Buddism, Longjing tea/Lungching/Dragon Well tea, Biluochun tea/Pi Lou Chun, Chrysanthemum tea, Dahongpao tea/Wuyi Mountain rock tea, Pu'er tea, Jasmine tea, White Milli-Silver Needle Tea, Xinyang Maojian Tea, Green tea 3) tea-things translation: teapot, tea pad, tea plate, tea pitcher, lid saucer, tea serving tray, teacup, cup saucer, tea towel tray, tea holder, tea towel, tea brush, water kettle, tea basin, covered bowl, teaspoon, tea canister, tea bowl 4. Situational dialogue: You and the foreign guest go to the restaurant and the foreign guest wants to order a cup of tea, how can you recommend it for him?

(3) Create the best internal and external events for the designed teaching components. Gagné (1977) defined nine external events that affect teaching (see Table 1) and believe that education around these arrangements can promote the internal events that constitute learning. Therefore, this paper takes these external events as the framework of curriculum design.

Table 1. Nine external events that affect teaching

\begin{tabular}{|c|c|}
\hline Events & Aims \\
\hline $\begin{array}{l}\text { 1. Attention-attracting or } \\
\text { motivation-triggering }\end{array}$ & Establish a learning pattern to lead learners' attention to the teaching purpose or related teaching direction. \\
\hline 2. Learning goals presentation & Establish expectations for expected behavior performance. \\
\hline $\begin{array}{l}\text { 3. Prerequisites or related } \\
\text { knowledge Recalling }\end{array}$ & Provide a solid point for learning and link what will be learned with known knowledge of students. \\
\hline $\begin{array}{l}\text { 4. New information } \\
\text { presentation }\end{array}$ & $\begin{array}{l}\text { Present new information, procedures, processes, problems or tasks to be learned. This is usually the focus } \\
\text { of speeches and written texts. Linking this to previously acquired knowledge can help students code it into } \\
\text { long-term memory. }\end{array}$ \\
\hline 5. Guidance & $\begin{array}{l}\text { Elaborate process the content presented in event } 4 \text {. Examples can be given as the form of storytelling, } \\
\text { description, discussion or any other form to make the content easier to remember. This step promotes the } \\
\text { establishment of coding and knowledge structure. }\end{array}$ \\
\hline 6. Exercises & $\begin{array}{l}\text { Exercises lead to learners' responses. This is related to what is learned based on clues and its purpose is } \\
\text { more than evaluation but to identify uncertainty and misunderstanding. }\end{array}$ \\
\hline 7. Feedback & Provide learners with information about their understanding of correctness. \\
\hline 8. Behavior measurement & Test the durative retention of acquired knowledge or skills. \\
\hline 9. Retention and transfer & $\begin{array}{l}\text { By strengthening what students have learned through interval exercises, "migration" means that students } \\
\text { can apply what he/she has learned to different situations. }\end{array}$ \\
\hline
\end{tabular}

1) Attention attracting or motivation triggering: 1 . The teacher asks "What do you know about the English 
expression of Chinese tea culture?" Through the answer, students find that they lack the ability to express, resulting in learning needs. 2. Play the TED animation "Animation reveals unknown tea culture" and remind students to pay attention to recording words and sentences about tea such as tea powder, tea brick, tea foam and other words about tea. Sentences like "Today, tea is the second most consumed beverage in the world, after water." are also worth noticing. Learners' interest is aroused by the video and their attention to the content of the teaching is caused by the method of recording the content related to the subject matter by the student.

2) Establish the expectation of the study: question: You and your foreign friend, foreign employer or foreign colleague goes to a restaurant, the foreign guest wants a cup of tea, and can you introduce and recommend to him/her?

3) Prerequisites or related knowledge recalling: How many words do you know about tea culture? Do group discussion and summary with the teachers' help.

4) New information presentation:

a) Tea culture knowledge (video).

b) terms and sentences of tea culture

c) The teacher shows how to introduce a kind of tea from the aspects of history, birthplace, origin, taste, color, smell, tea set and so on.

5) Guidance: Do elaborate process on teaching through video examples and analysis of knowledge about tea culture, classroom discussions organizing to promote the establishment of knowledge structure in students' minds.

6) Exercises: review the situation created before: You and your foreign friend, foreign employer or foreign colleague goes to a restaurant, the foreign guest wants a cup of tea, can you introduce and recommend to him/her? Let the students carry on group practices that strengthen the application and cultivate students 'communication ability.

7) Feedback: the teacher reviews the performance of students in step 6) and points out their errors.

8) Behavior measurement: Students are required to record contextual video for the scenario in step 6) within two weeks.

9) Retention and transfer: the method of spreading tea culture learned in classes extends to the level of spreading Chinese culture.

\subsection{Develop}

DEVELOP is the preparation of materials to be used in teaching. The development of resources belongs to the problematic stage of teaching design. Developers should consider the specific level of the content input into the study and the adaptability of the existing materials to the teaching purpose and so on. Considering that we pursue cost-effectiveness as much as possible, we should apply as many existing resources as possible in teaching design and make full use of network resources.

\subsection{Implement}

In the ADDIE model, there are two types of implements. One is the implementation activity in teaching design, which is called the pilot test or the field test. The other is the implementation when the designed course is put into use after the DEVELOP stage is completed. The implementation phase emphasizes the development of a learning management system that fully meets the requirements of the situation. In the teaching implementation, the teacher can set up a quantitative table to record students' initial level, performance, group performance, degree of acquisition, and the feasibility of further learning (see Table 2).

Table 2. Quantitative table of students' learning grade

\begin{tabular}{lllll}
\hline Names & Class A & Class B & Class C & Class D \\
\hline Initial level & & & & \\
Classroom performance & & & & \\
Group performance & & & & \\
Degree of acquisition & & & & \\
Feasibility of further learning & & & & \\
\hline
\end{tabular}


Initial level: the pre-teaching questionnaire investigates the initial level of students. The questionnaire is divided into two parts: translation and writing. In the translation part, the students' understanding of the English expression of basic tea culture is investigated. The scoring rules are shown in Table 3. Each term that meets all the three standards gets 1 score. In the writing part, the students' overall expression level of tea culture in English is investigated and the scoring rules are shown in Table 4. The total score was divided into four grades: Grade A 20-15 points, Grade B 14-10 points, Grade C 9-5 points, Grade D 4-0 points. For details of the test, see Appendix B.

Table 3. Scoring standard for translation

\begin{tabular}{lll}
\hline Standards & \\
\hline Accordance with both English and Chinese terms & Correctness & Compliance with the custom of the Chinese expression \\
\hline
\end{tabular}

Table 4. Scoring criteria of writing

\begin{tabular}{|c|c|c|c|}
\hline Dimensions & Idea and interpretation ( $\left.5^{\prime}\right)$ & Pragmatic Competence (3') & Writing norms (2’) \\
\hline Descriptions & $\begin{array}{ll}\text { - } & \text { pertinent to the subject } \\
\text { - } & \text { rich in content } \\
\text { - } & \text { coherent } \\
\text { - } & \text { fluent in expression } \\
\text { - } & \text { rigorous in structure }\end{array}$ & $\begin{array}{ll}\text { - } & \text { grammatical correct } \\
\text { - } & \text { accurate wording } \\
\text { - } & \text { rich in words } \\
\text { - } & \text { sufficient word account }\end{array}$ & $\begin{array}{ll}\text { - } & \text { correct in form and spelling } \\
\text { - } & \text { correct in punctuation } \\
\text { - } & \text { neat }\end{array}$ \\
\hline
\end{tabular}

Classroom performance: scores should be given according to students' degree of enthusiasm, participation and attitude in class, the scoring criteria shown in Table 5. The total score was divided into four levels: Grade A, very active, 20-15 points; Grade B, active, 14-10 points; Grade C, not active, 9-5 points; Grade D, very inactive, 4-0 points.

Table 5. Scoring criteria for class performance

\begin{tabular}{|c|c|c|}
\hline Dimensions & Participation 12 & Degree of concentration 8 \\
\hline & - $\quad$ question answering 4 , & - $\quad$ high 8 \\
\hline & - $\quad$ participation of group discussions 4 & - $\quad$ medium 4 , \\
\hline & presentation 4 & low 0 \\
\hline
\end{tabular}

Group Performance: scores should be given according to the accuracy, smoothness of the words used by students and whether the word conforms to intercultural exchanges. Grade A 20-15 points, Grade B 14-10 points, Grade C 9-5 points, Grade D 4-0 points.

Each of the five items accounted for $20 \%$ in a total of 100 points. Therefore, each student will have a final score that represents their comprehensive achievement in tea culture class.

\subsection{Evaluate}

EVALUATE is the last stage of the ADDIE model but the evaluation can occur at any stage in that self-evaluation, self-reflection, self-improvement can happen in any procedure. It includes five aspects of evaluation.

Material evaluation: Firstly the experienced English teaching experts are invited to read the learning objectives and the manuscripts for proof. Then students who are not teaching objects (but have the remarkable characteristics of the teaching objects) are invited to read the teaching materials and his interest in the contents is investigated by questionnaire (see Appendix C).

Process evaluation: The evaluation of the process refers to the evaluation of the teaching design process itself. At every step of the design, the efficiency of the work and the feasibility of improvement are checked.

Learners' response: In this part of the test, the first of the four results test proposed by Kirkpatrick (1959) is adopted, that is, to evaluate the learner's response. The evaluation of students' response is generally carried out after the end of the teaching by self-report survey in the form of the questionnaire. Students were investigated about their views on teaching clarity, logical connection of each part, quality of teaching strategy, the 
effectiveness of teachers, comfort of the environment (Gagné et al., 2005). For details of the questionnaire, see Appendix C.

The achievements of learners: This test can detect whether the learners meet the requirements of the teaching objectives and the test results can test the effectiveness of the teaching. It is also the basis of whether the students can pass the test. In this class, the learning achievement test is carried out in the form of video scoring.

The effect of teaching: This kind of evaluation focuses on whether the content can be transferred to other application environments. This class should test whether students can improve their intercultural ability after learning the English expression method of tea culture and whether they can actively learn intercultural knowledge and learn the rich connotation of Chinese culture.

\section{Conclusion}

For the purpose of intercultural education, this paper carried out the college English teaching design of Chinese tea culture based on the ADDIE model and analyzed its various steps to find that the design of Chinese tea culture based on the ADDIE model is feasible, logical and complete. It meets the requirements of intercultural education from the aspect of theory teaching to practical teaching.

\section{Acknowledgments}

This paper is one of the research achievements of "Research on the Solution of the Contradiction Between Chinese Cultural Promotion and Chinese Cultural Aphasia in College English Teaching" (No. HB18YY033) supported by Social Science Foundation of Hebei Province in 2018.

\section{References}

Bo, C. L. (2014). Research on the Application Mode of the ADDIE Model in Micro curriculum Design. Journal of Teaching and Management, 24, 90-93.

Gagné, R. M. (1977). Analysis of objectives. In L. J. Briggs (Ed.), Instructional design: Principles and applications. Englewood Cliffs, NJ: Educational Technology Publications.

Gagné, R. M., Wager, W. W., Goals, K. C., Keller, J. M. (2005). Principles of Instructional Design. Shanghai: East China Normal University Press.

Hu, W. Z. (2013). How to Position Intercultural Communicative Competence in Foreign Language Teaching. Foreign Language World, 6, 2-8.

Huang, Y. (2015). A Study on the Lack of Mother Culture in College English Teaching. China Adult Education, $15,175-177$.

Kaufman, R. A. (1996). Strategic thinking: A guide to identifying and solving problems. Alexandria. VA: American Society of Training and Development.

Kirkpatrick, D. L. (1959). Techniques for evaluating training programs. Journal of the American Society of Training Directors, 13, 3-9, 21-26.

Qi, H. X. (2016). The Enlightenment of the ADDIE Model to Flipping Class Teaching Design. China Adult Education, 17, 107-109.

Rossett, A. (1988). Training needs assessment. Englewood Cliffs, NJ: Educational Technology Publications.

Skinner, B. F. (1968). The technology of teaching. New York: Appleton.

Van Merriënboer, J. J. G., Clark, R. E., \& de Croock, M. B. M. (2002). Blueprints for Complex Learning. New York: Macmillan. https://doi.org/10.1007/BF02504993

Wang, S. R. (2018). Guidelines on College English Teaching. College Foreign Language Teaching and Research, 7.

Xu, J. S. (2017). Practice and Exploration of Developing Micro video Based on the ADDIE Model. Occupation, $15,124-125$.

Yang, Y., \& Zhuang, E. P. (2007). Construction of the framework of intercultural communicative competence in foreign language teaching. Foreign Language World, 4,13-21, 43.

Yao, J. J., Wang, S. C. (2017). Chemistry reversal class Design based on the ADDIE model: A case study of oxide reduction in Human Education Edition. Education in Chemistry, 7, 37-40, 44.

Zhang, H. L. (2007). Intercultural Approach to Foreign Language Teaching. Shanghai: Shanghai Foreign Language Education Press. 


\section{Appendix A}

\section{Questionnaire of Attitude}

1. It is necessary to learn the English expression of Chinese culture.
A Yes
B No
C Not sure

2. There is no need for Chinese culture to be taught in English classes.
A Yes
B No
C Not sure

3. Learning Chinese culture will affect my intercultural communicative competence.
A Yes
B No
C Not sure

4. When communicating with foreigners, I am willing to act as a cultural emissary to introduce Chinese culture to foreign friends.
A Yes
B No
C Not sure

5. I agree with the view that one of the purposes of learning English is to publicize Chinese national culture to foreign countries.
A Yes
B No
C Not sure

6. Understanding Chinese culture can promote my English learning.
A Yes
B No
C Not sure

7. The study of Chinese culture is not as important as that of foreign culture in English learning.
A Yes
B No
C Not sure

8. I will pay attention to the online resources of introducing Chinese culture in English on the Internet.
A Yes
B No
C Not sure

9. I will use reading, learning to introduce Chinese culture in English books, audio-visual and other materials to learn the English expression of Chinese culture.
A Yes
B No
C Not sure

10. I hope the teacher can teach the English expression of Chinese culture.
A Yes
B No
C Not sure

11. I hope that the teacher can supplement the relevant knowledge of Chinese culture in the English class.
A Yes
B No
C Not sure

12. If I have knowledge of Chinese culture in English expression, I will be more confident in intercultural communication.
A Yes
B No
C Not sure 


\section{Appendix B}

\section{Pretest of Chinese tea culture}

1. Translation: 10'

savoring tea
strong tea
imbibe
sips
tea sets
tea brewing
refreshing drinks
green tea
black tea
oolong tea

2. Use the words above to write a composition that introduces the Chinese tea culture (more than 100 words) 10'

\section{Appendix C}

\section{Questionnaire of teaching evaluation}

1. The instructional objectives are clear.

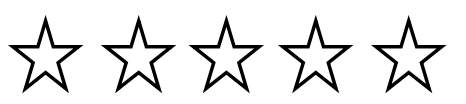

2. The logic of pre-class introduction, content learning, situational exercise and after-class exercise in this class is closely connected.

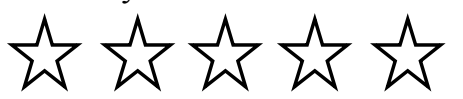

3. This kind of teaching method can make me improve my learning effect.

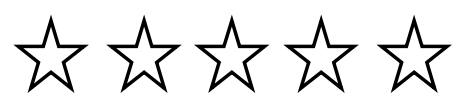

4. The role of teachers in teaching is significant.

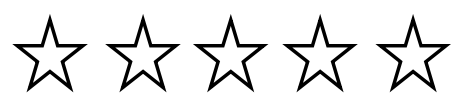

5. Learning in the teaching environment created in this lesson is very comfortable and happy.

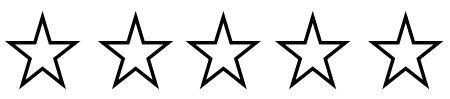




\section{Appendix D}

\section{Students' survey}

(The first question is a choice question, please answer 2-7 questions according to facts).

1. The ideological concept of teaching materials is correct, there are no political errors.
A Yes
B No
C Not sure

2. The teaching materials are highly readable and involve a wealth of knowledge.

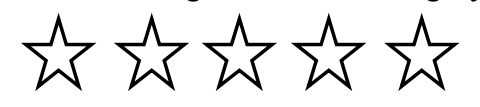

3. There is a high interest in teaching materials.

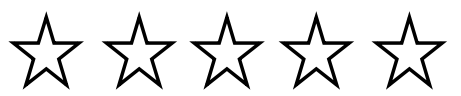

4. There is high practicability in teaching materials.

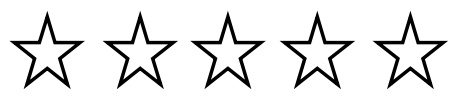

5. There are high characteristics and innovation in teaching materials.

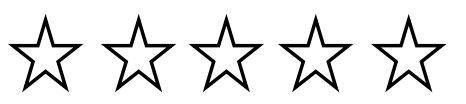

6. The difficulty degree of knowledge in teaching materials is mezzo.

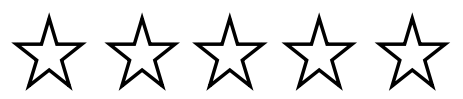

7. I want to continue to learn something like that.

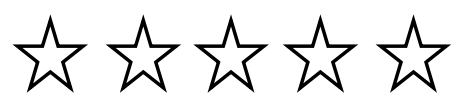

\section{Copyrights}

Copyright for this article is retained by the author(s), with first publication rights granted to the journal.

This is an open-access article distributed under the terms and conditions of the Creative Commons Attribution license (http://creativecommons.org/licenses/by/4.0/). 